\title{
Satisfação e responsividade: formas de medir a qualidade e a humanização da assistência à saúde
}

\author{
Satisfaction and responsiveness: ways to measure \\ quality and humanization of health assistance
}

Jeni Vaitsman 1

Gabriela Rieveres Borges de Andrade 2

\footnotetext{
1 Departamento de Ciências Sociais, ENSP/Fiocruz. Rua Leopoldo Bulhões 1.480 , sala 916 , Manguinhos, 21041-210, Rio deJaneiro RJ. vaitsman@ensp.fiocruz.br 2 ENSP/Fiocruz.
}

\begin{abstract}
The paper discusses the concepts of "user's satisfaction", "responsiveness", "humanization" and patient's rights, focusing on their convergences and differences, as well as their reliability when used in the evaluation of health services and systems. Satisfaction and responsiveness are viewed as operational concepts, integrating user's views, while humanization and patients's rights concern to normative principles which serve as grounds for policies and programs. While satisfaction studies put a light on the patient's role in health services and systems, the concept of responsiveness strengthened its position, giving him the status of an individual and citizen, that is, a subject of universal rights. This conceptual and methodological framework is viewed as part of a paradigm of rights - individual, social and political -, which is used also in the area of evaluation of quality and health care.
\end{abstract}

K ey words U ser's satisfaction, Responsiveness, Humanization, Patient's rights
Resumo 0 artigo faz uma discussão dos conceitos de "satisfação do usuário", "responsividade", "humanização" e "direitos do paciente". Ressaltam-se suas convergências e diferenças, bem como sua pertinência nas pesquisas de avaliação de serviços e sistemas de saúde. Satisfação e responsividade são analisados como concei tos operacionais que incorporam a visão do usuário; humanização e direitos do paciente referem-se a princípios normativos que orientam políticas e programas. Enquanto as pesqui sas de satisfação deram destaque ao lugar dos pacientes nos serviços e sistemas de saúde, o conceito de responsividade fortaleceu sua posição, dando ao paciente 0 status de um indivíduo/cidadão, ou seja, de um sujeito de direitos válidos universalmente. Esse arcabouço conceitual e metodológico é parte de um paradigma de direitos aplicado também na área da avaliação da qualidade e da assistência à saúde.

Palavras-chave Satisfação do usuário, Responsividade, Humanização, Direitos do paciente 


\section{Introdução}

Este artigo é parte de uma pesquisa sobre satisfação de usuários em um serviço de assistência à saúde na rede pública no Rio de Janeiro "Gestão de qualidade e satisfação dos usuários em serviços públicos de saúde: um estudo piloto no Instituto de Pesquisa Clínica Evandro Chagas". Ao investigarmos as metodologias usadas em pesquisas de satisfação do usuário, percebemos as similaridades, convergências e superposições entre alguns termos e conceitos que, de forma nem sempre clara, dão destaque ao lugar do usuário na avaliação dos serviços e sistemas de saúde.

No ano 2000, a Organização Mundial de Saúde - OM S introduziu nas pesquisas de avaliação em saúde o conceito de "responsividade" dos sistemas de saúde, em contraposição ao de "satisfação", utilizado desde a década de 1960. Enquanto as pesquisas de "satisfação" focalizavam as distintas dimensões que envolvem 0 cuidado à saúde, desde a relação médico-paciente até a qualidade das instalações e dos profissionais de saúde, responsividade surgiu referindo-se aos aspectos não-médicos do cuidado. Esses dois conceitos são discutidos, tanto em relação aos contextos históricos em que surgiram, quanto ao modo como vêm sendo aplicados em metodologias de avaliação de serviços e sistemas de saúde, com destaque para seus limites e vantagens em diferentes situações.

As metodologias que incorporam a visão do usuário são vistas como parte de um paradigma no qual se reafirmam princípios relativos a direitos individuais e de cidadania, tais como expressos nos conceitos de humanização e direitos do paciente. A partir dos anos 90 , a idéia de humanização passa a fazer parte do vocabulário da saúde, inicialmente como um conjunto de princípios que criticam o caráter impessoal e desumanizado da assistência à saúde, e que mais tarde são traduzidos em diferentes propostas visando modificar as práticas assistenciais. Destacamos a convergência desse conceito, cujo eixo central é a dimensão humana, individual e ética do atendimento, com a concepção de direitos do paciente.

0 desenvolvimento histórico desse arcabouço conceitual e metodológico na área da avaliação da qualidade e da assistência à saúde tem como uma de suas implicações a ampla utilização de pesquisas de satisfação do usuário e, mais recentemente, de responsividade, ou seja, da visão ou da experiência dos usuários dos serviços de saúde. Em um sentido mais amplo, essas pesqui sas permitem verificar o modo como direitos - individuais e de cidadania - são observados no acesso e utilização dos serviços e sistemas de saúde.

\section{As pesquisas de satisfação: uma contextualização}

A partir do final dos anos 70, tanto na Europa quanto nos EUA, vários movimentos - ora entrando em conflito, ora reforçando-se mutuamente -, que fizeram parte de um processo mais amplo de transformações econômicas, políticas e culturais, deram aos pacientes um novo lugar na avaliação dos serviços de saúde. No setor público, os custos crescentes dos serviços de saúde foram um dos elementos que favoreceram as políticas reformadoras e de restrição de gastos, e o surgimento de novos modelos de gestão visando maior transparência, qualidade e eficiência dos serviços.

As primeiras pesquisas no campo da avaliação em saúde, ainda na década de 1970, referiam-se à satisfação do paciente. 0 objetivo era conseguir melhores resultados clínicos, por meio da adesão ao tratamento, em três dimensões: comparecimento às consultas; aceitação das recomen dações e prescrições e uso adequado dos medicamentos (Williams, 1994). Estas pesquisas foram antecedidas por estudos que, na área das Ciências Sociais e H umanas (Parsons, 1951; Szasz \& Hollander, 1956; Coser, 1956; 1962; Cartwright, 1964), focalizavam as relações médico-paciente no contexto da clínica ou do ambiente hospitalar (Williams, 1994; Siztia \& Wood, 1997; Donabedian, 1984).

Existem vários model os que medem a satisfação do paciente, mas todos têm como pressupostos as percepções do paciente em relação às suas expectativas, valores e desejos (LinderPelz, 1982; Williams, 1994; De Silva, 1999). Satisfação do paciente pode ser definida como "as avaliações positivas individuais de distintas dimensões do cuidado à saúde" (Linder-Pelz, 1982). Estas avaliações expressariam uma atitude, uma resposta afetiva baseada na crença de que o cuidado possui certos atributos que podem ser avaliados pelos pacientes (Sitzia \& Wood, 1997).

Com Donabedian (1984), a noção de satisfação do paciente tornou-se um dos elementos da avaliação da qualidade em saúde, ao lado da avaliação do médico eo da comunidade. A qua- 
lidade passou a ser observada a partir desses três ângulos, de forma complementar e, ao mesmo tempo, independente. 0 conceito de qualidade desenvolvido por Donabedian permitiu avançar no sentido de incorporar os não especialistas - no caso, os pacientes - na definição de parâmetros e na mensuração da qualidade dos serviços. A partir de então, os usuários não puderam mais ser ignorados, e a idéia de satisfação do paciente como um atributo da qualidade tornou-se um objetivo em si e não apenas um meio de produzir a adesão do paciente ao tratamento, como era comum nos objetivos de estudos anteriores (Shaw, 1986; Vuori, 1987; Williams, 1994).

Aos poucos, quando "satisfação do usuário" passou a denominar um conjunto amplo e heterogêneo de pesquisas, com o objetivo de saber a opinião dos usuários de serviços de um modo geral, públicos ou privados, o termo usuário também passa a ser utilizado nas pesquisas de avaliação em saúde. Essas pesquisas vieram focalizar as distintas dimensões que envolvem o cuidado à saúde, desde a relação médico-paciente até a qualidade das instalações do serviço, passando pela qualidade técnica dos profissionais de saúde.

Dois outros termos, a partir das duas últimas décadas, começam a ser usados ainda, paral elamente, aos de paciente e usuário: consumidor e cliente. Sitzia e Wood (1997) defendem a idéia de que o termo consumidor confere maior dignidade ao relacionamento profissional/paciente, ao contrário do tradicional termo "paciente", que estaria associado à falta de poder e dependência em relação ao médico.

Essa emergência se dá em um momento político-cultural de crítica às relações de poder manifestas na linguagem - e principalmente nas expressões polares em que o primeiro termo é visto como subordinando o segundo, como, por exemplo, na expressão "médico-paciente". 0 crescimento dos movimentos de consumidores e usuários dos serviços públicos exigindo melhores produtos e serviços coloca na agenda o empowerment dos sujeitos - entre os quais se encontram agora os "pacientes".

Com isso, cria-se também um campo propício e um mercado para pesquisas de avaliação a partir das percepções dos usuários, que geralmente passam a ser feitas por meio da coleta direta de informações junto aos respondentes por meio de questionários com respostas fechadas para a produção de dados estatísticos, os surveys. Até porque as reformas orien- tadas para a qualidade na administração públi$\mathrm{ca}$, ao visarem aos custos crescentes do setor saúde, também vêm exigir métodos que meçam a qualidade dos serviços de forma "objetiva", o que, supunha-se, era feito por pesquisas usando métodos quantitativos.

0 termo consumidor vincula-se ao ideário eficientista, objetivista e de ênfase no mercado que se tornou predominante nos anos $80 \mathrm{e}$ orientou as reformas na administração pública. Alguns autores associam o consumidor a um indivíduo racional, consciente de suas escolhas e capaz de defender seus direitos. Esta visão seria a do "bom consumidor" - aquele que faz escolhas e assimila informações, para cumprir seu papel. O u seja, sujeito de desejo, vontade, informação e direitos (O wens \& Bachelor, 1996; De Silva, 1999). Outra distinção que pode ser feita é que, enquanto o termo "cliente" refere-se a um indivíduo ao qual concernem certos direitos, "consumidor" sugeriria que o indivíduo é parte de um grupo de usuários que podem agir em conjunto para garantir direitos (De Silva, 1999).

Pode-se fazer ainda outra distinção, entre usuário e cidadão. Como usuário, pode-se desejar níveis mais altos de qualidade do serviço, mas, como cidadão, pode-se achar que os recursos seriam mais bem alocados em outra parte. A noção de usuário é mais geral e permite abranger os indivíduos que utilizam serviços públicos e privados, sejam eles vistos como clientes, consumidores e/ou cidadãos (Dinsdale et al., 2000).

É preciso levar em conta algumas diferenças rel evantes quando se avaliam serviços públicos e privados. No setor público, o usuário pode se colocar ora como consumidor, avaliando os serviços do ponto de vista de seus ganhos individuais, ora como cidadão, avaliando os serviços ao levar em conta a sociedade como um todo. Como consumidor, ele pode desejar um tempo de espera menor para a consulta e atendimento mais ágil, mas, como cidadão, pode querer que todas as pessoas sejam atendidas, implicando um tempo de espera maior. No que se refere à escolha, no setor privado, o cliente pode procurar outro serviço ou outro profissional, enquanto no setor público essa possibilidade é limitada, quando não impossível (Dinsdale et al., 2000).

No Brasil, movimentos e associações reivindicando melhores serviços, seja como consumidores ou cidadãos/usuários de serviços públicos, somente tomaram força após os anos 
80, com a redemocratização. Por isso mesmo, as pesquisas de satisfação de usuários tornaram-se mais comuns a partir da segunda metade da década de 1990 (Kotaka et al., 1997; CNI/ Ibope, 1999).

\section{Metodologias das pesquisas de satisfação}

São várias as metodologias de pesquisa de satisfação do usuário. U ma das mais conhecidas foi desenvolvida por Parasuraman (1988), para avaliar serviços privados de diferentes naturezas. Avalia cinco dimensões do atendimento - agilidade, confiabilidade, empatia, segurança e tangibilidade (ver definições no quadro 2) -, a partir do cálculo da taxa de satisfação relativa e do cálculo de GAPs, expressão inglesa que significa "intervalo".

Essa metodologia considera a expectativa do usuário em relação ao serviço e a importância que ele confere a cada uma das dimensões. A partir de notas de 1 a 10 aos diversos aspectos do atendimento, calcula-se a taxa de satisfação relativa que é a diferença entre a satisfação e a expectativa. Também é feito o cálculo de
GAPs, que consiste na diferença, em porcentagem, entre a taxa de satisfação relativa e a nota da satisfação, resultando em um valor que significa o quanto falta para o usuário ficar plenamente satisfeito com o serviço.

Para Donabedian (1984; 1990), a avaliação do ponto de vista dos usuários é feita, sobretudo, por meio da categoria aceitabilidade, que se refere à conformidade dos serviços oferecidos em relação às expectativas e aspirações dos pacientes e seus familiares. Conceitualmente, essa proposta é similar aos pressupostos de Parasuraman, pois também implica expectativas, atendidas ou não. Por outro lado, metodologicamente, a dimensão da aceitabilidade comporta as variáveis através das quais os pacientes podem influir de forma mais direta na definição e avaliação da qualidade dos serviços de saúde tais como condições de acessibilidade ao serviço, relação médico-paciente, adequação das dependências e instalações, preferências em relação aos efeitos e custos do tratamento, bem como tudo aquilo que o paciente considera justo ou equânime.

A forma pela qual muitas dessas pesquisas buscam saber a opinião do paciente é pergun-

Quadro 1

Responsividade / Satisfação / Humanização / Direitos do Paciente.

\begin{tabular}{|c|c|c|c|c|}
\hline \multirow[t]{2}{*}{ Categorias } & \multicolumn{4}{|c|}{ Conceitos } \\
\hline & Responsividade & Satisfação & Humanização & Direitos do Paciente \\
\hline 1) Dignidade & $x$ & $x$ & $x$ & $\mathrm{x}$ \\
\hline 2) Confidencialidade & $x$ & & $x$ & $\mathrm{x}$ \\
\hline 3) Autonomia & $x$ & & $x$ & $\mathrm{x}$ \\
\hline 4) Apoio Social & $\mathrm{x}$ & & $\mathrm{x}$ & $\mathrm{x}$ \\
\hline 5) Comunicação/ & & & & \\
\hline informação & $\mathrm{x}$ & $\mathrm{x}$ & $\mathrm{x}$ & $\mathrm{x}$ \\
\hline 6) Agilidade & $\mathrm{x}$ & $\mathrm{x}$ & $\mathrm{x}$ & \\
\hline 7) Instalações/ & & & & \\
\hline ambiente físico & $\mathrm{x}$ & $\mathrm{x}$ & $\mathrm{x}$ & $\mathrm{x}$ \\
\hline 8) Escolha & $\mathrm{x}$ & & & \\
\hline 9) Aspectos interpessoais & & $\mathrm{x}$ & & \\
\hline 10) Competência/ & & & & \\
\hline qualidade técnica & & $\mathrm{x}$ & & $\mathrm{x}$ \\
\hline 11) Conveniência & & $\mathrm{x}$ & & $\mathrm{x}$ \\
\hline 12) Finanças & & $\mathrm{x}$ & & $\mathrm{x}$ \\
\hline 13) Eficácia/resolução & & $x$ & $\mathrm{x}$ & $x$ \\
\hline 14) Continuidade & & $\mathrm{x}$ & $\mathrm{x}$ & $\mathrm{x}$ \\
\hline 15) Viabilidade & & $\mathrm{x}$ & & \\
\hline 16) Confiabilidade & & $\mathrm{x}$ & & \\
\hline 17) Empatia & & $x$ & & \\
\hline 18) Garantia & & $\mathrm{x}$ & & \\
\hline 19) Receptividade & & $\mathrm{x}$ & $\mathrm{x}$ & \\
\hline 20) Gestão participativa & & & $\mathrm{x}$ & \\
\hline
\end{tabular}


Quadro 2

Definição das categorias.

\section{Categoria Definição}

1) Dignidade

Ser tratado com respeito e consideração, ser bem recebido nas unidades de saúde, tratado respeitosamente em qualquer circunstância. Ser examinado e tratado tendo a privacidade e o direito de sigilo das informações sobre sua doença respeitados (OM S, 2000b).

Na revisão de Sitzia \& Wood (1997) o respeito faz parte da categoria "aspectos interpessoais".

(...) acesso a atendimento digno e de qualidade no decorrer da gestação, parto e puerpério (PHPN , 2002). Todos os usuários saberão quem são os profissionais que cuidam de sua saúde; as unidades de saúde garantirão os direitos dos usuários (...) (PNH, 2002).

Ter um atendimento digno, atencioso e respeitoso. Ser identificado e tratado pelo nome (e não por números, códigos; de modo genérico, desrespeitoso ou preconceituoso). Poder identificar as pessoas envolvidas na sua assistência, através de crachás visíveis, legíveis e que contenham nome, completo, função e o cargo. Ter assegurada sua privacidade; individualidade e o respeito aos seus valores éticos e culturais (Direitos dos usuários, 1999). I gualdade da assistência à saúde, sem preconceitos ou privilégios de qualquer espécie (lei 8.080).

2) Confidencialidade

As consultas devem ser conduzidas de maneira a que a privacidade seja protegida e garantida a confidencialidade de toda a informação fornecida pelo paciente, mantendo-a em arquivos médicos confidenciais, exceto se a informação for necessária para o tratamento para outros profissionais de saúde (OM S, 2000).

(...) a confidencialidade de toda e qualquer informação pessoal (Direitos do paciente, 1999).

3) Autonomia

Ter informação sobre as opções e alternativas de tratamento e permissão para tomar decisões sobre o tipo de tratamento, depois de discutir com o profissional de saúde, devendo ser encorajado a questionar. Poder recusar o tratamento. Ter o consentimento do paciente antes de iniciar tratamento ou testes (OMS, 2000).

Consentir ou recusar, de forma livre, voluntária e esclarecida, com adequada informação, procedimentos para diagnósticos ou terapêuticos a serem nele realizados (Direitos do paciente, 1999).

4) Apoio Social

Permissão aos pacientes internos de visitas de parentes e amigos, provisão de comida e outros artigos não providos pelo hospital; permissão de práticas religiosas não prejudiciais às atividades do hospital e que não firam a sensibilidade de outros indivíduos; acesso a rádios, jornais ou algum outro material de leitura, algum tipo de apoio para os pacientes terminais e no pós-hospitalar (OM S, 2000).

Acompanhamento de pessoas da rede social do paciente, de sua livre escolha (PNH , 2002).

Ser acompanhado, se assim o desejar, nas consultas e internações por pessoa por ele indicada (Direitos do paciente, 1999).

5) Comunicação/ Informação

O profissional de saúde deve ouvir o paciente cuidadosamente e fornecer explicações de modo que o paciente possa entender, dispondo de tempo suficiente para esclarecer todas as suas dúvidas (OM S, 2000).

As unidades de saúde garantirão as informações aos usuários (PNH , 2002).

Receber informações claras, objetivas e compreensíveis sobre: hipóteses diagnósticas, diagnósticos realizados, exames solicitados, ações terapêuticas; riscos e ben efícios do tratamento, etc. Ser prévia e expressamente informado quando o tratamento proposto for experimental ou fazer parte de pesquisa. A cessar, a qualquer momento, o seu prontuário médico (Direitos do paciente, 1999). 
Quadro 2 (continuação)

Categoria Definição

6) Agilidade

Unidades de saúde devem ser geograficamente acessíveis, levando em conta a distância, o transporte e o terreno. Os pacientes devem conseguir cuidado rápido em emergências e o tempo de espera por consultas e tratamento deve ser curto (OMS, 2000).

Sitzia \& Wood (1997) tempo de espera na categoria "conveniência".

Serão reduzidas as filas e o tempo de espera (...) (PNH, 2002).

7) Instalações/ O meio no qual o cuidado de saúde é provido deve incluir vizinhança e arredores limpos, mobília Ambiente físico adequada, comida saudável e de boa procedência, ventilação suficiente, água limpa, banheiros e roupas limpos. Devem ser realizados procedimentos regulares de limpeza e manutenção da edificação e alicerces do hospital (OMS, 2000).

Sinais de direção claros, equipamentos e mobília adequados, atmosfera agradável (Sitzia \& Wood, 1997).

(...) promover ambiência acolhedora e confortável (PNH , 2002).

Ter um local digno e adequado para o atendimento (Direito do paciente, 1999).

8) Escolha

Possibilidade, na unidade de saúde, de escolher os profissionais de saúde. O s indivíduos devem poder ter acesso a uma segunda opinião em casos de doenças severas ou crônicas ou cirurgia (OM S, 2000).

9) Aspectos Modo com que cada profissional de saúde interage pessoalmente com os pacientes, ou seja, respeito, interpessoais cortesia, interesse, animosidade (Sitzia \& Wood, 1997).

10) Competência/ Qualidade técnica

Envolve evitar riscos desnecessários e erros médicos ( Sitzia \& Wood, 1997).

Estimular práticas resolutivas, racionalizar e adequar o uso de medicamentos eliminando ações desnecessárias (PNH, 2002).

11) Conveniência Localização da unidade de saúde (distância, transporte, etc.) , tempo de espera (para cirurgias, atendimento, exames), sistema de notificação, recepção, facilidade de acessar o médico, atendimento domiciliar (Sitzia \& Wood, 1997).

12) Finanças 0 paciente tem o direito de ter acesso às contas detalhadas referentes ao seu tratamento, internação e outros procedimentos médicos (Direitos do paciente, 1999).

Fatores envolvidos no pagamento do serviço médico (Sitzia \& Wood, 1997).

13) Eficácia/Resolução Resultados dos serviços prestados, ou seja, melhoria ou manutenção da saúde (Sitzia \& Wood, 1997).

Atendimento acolhedor e resolutivo baseado em critérios de risco (PNH , 2002).

14) Continuidade Constância do cuidado (Sitzia \& Wood, 1997).

Garantia de continuidade de assistência com sistema de referência e contra-referência (PNH, 2002).

Integralidade de assistência, entendida como um conjunto articulado e contínuo das ações e serviços preventivos e curativos, individuais e coletivos, exigidos para cada caso em todos os níveis de complexidade do sistema (Brasil, 1988).

15) Viabilidade M édicos e profissionais de saúde em número suficiente. Recursos médicos.

16) Confiabilidade

Os serviços cumprirem o que prometeram e estarem habilitados para realizar o serviço (Parasuraman, 1999). 
Quadro 2 (continuação)

Categoria Definição

17) Empatia

Cuidado e atenção individualizada dispensada aos usuários. Incluem as dimensões acesso, comunicação e atendimento ao consumidor (Parasuraman, 1999).

18) Garantia

Serviço dos funcionários aliado à cortesia e habilidade de seu desempenho, inspirando confiança

(Parasuraman, 1999).

19) Receptividade

Prontidão em ajudar e responder às necessidades dos usuários (Parasuraman, 1999).

20) Gestão

participativa

As unidades de saúde garantirão gestão participativa aos seus trabal hadores e usuários (...) (PNH , 2002).

Participação da comunidade (Brasil, 1988).

tando o quão satisfeito ele está - ou ficou - com os serviços prestados pela unidade de saúde. A despeito das pesquisas de satisfação do usuário serem cada vez mais utilizadas para a construção de indicadores de qualidade dos serviços de saúde, vários problemas conceituais e metodológicos se colocam, como por exemplo, em que momento do atendimento o usuário deve ser abordado, que tipo de pergunta e de escala utilizar e o que exatamente avaliar.

U ma das críticas mais freqüentes às pesquisas de satisfação recai sobre 0 aspecto subjetivo da categoria "satisfação", que possui diversos determinantes como: grau de expectativa e exigência individuais em relação ao atendimento e características individuais do paciente como idade, gênero, classe social e estado psicológico (Sitzia \& Wood, 1997). 0 aspecto da expectativa é um dos mais complexos, pois os pacientes podem ter aprendido a diminuir as suas expectativas quanto aos serviços e uma boa avaliação de um serviço pode ser fruto de uma baixa capacidade crítica dos usuários. 0 contrário também pode acontecer, ou seja, uma avaliação mais baixa pode ser feita por pacientes com alto grau de exigência.

Outra crítica éa ausência de conseqüências práticas dessas avaliações; ou seja, elas produzem efetivamente uma melhoria na qualidade dos serviços? Basta dizer que alguns estudos apontam que as avaliações longitudinais muitas vezes mostram resultados decrescentes, já que a visão crítica dos entrevistados tende a aumentar.

Os resultados da maioria das pesquisas de avaliação, tanto nacionais como internacionais, têm sido bastante positivos em relação aos serviços de saúde, especialmente nas pesquisas com respostas fechadas, como são os surveys (Pascoe, 1983; Kotaka et al., 1997; RamirézSanchez et al., 1998; CNI//bope, 1999). O u seja, na grande maioria dos estudos realizados, quem utiliza os serviços - sejam eles chamados de pacientes ou usuários - são muito pouco críticos em relação à sua qualidade.

Para Williams (1994), uma avaliação positiva não quer dizer necessariamente que houve avaliação crítica; pode expressar ausência de opinião e/ou a aceitação do paternalismo médico. 0 significado da satisfação do paciente ou usuário dependeria do papel que este se atribui em relação ao sistema de saúde, aspecto que não costuma ser apreendido pelos surveys. Williams sugere que a compreen são das visões dos usuários dos serviços deve passar primeiro pelo entendimento do sentido de seus direitos e deveres; em outras palavras, que tipo de papel eles pensam ser 0 seu. As pesquisas de satisfação partem geralmente do pressuposto de que todos os usuários estejam desempenhando um papel crítico e acabam por interpretar os dados de acordo com isso: a possibilidade da aceitação passiva do serviço não costuma ser considerada.

Alguns autores ressaltam que, no setor público, a avaliação feita a partir dos usuários envolve uma interação mais complexa de elementos, incluindo os que influenciam as percepções sobre os serviços públicos. 0 gratitude bias (Bernhart, 1999) - sentimento de gratidão - seria comum em países periféricos, dificultando uma visão mais crítica do atendimento. Os pacientes evitariam criticar os serviços devido a este viés, tanto pelo medo de perder o acesso, quanto à relação de dependência aos profissionais de saúde. U m dos elementos que influenciam as per- 
cepções dos serviços do setor público é a confiança dos cidadãos no governo, nos políticose nos servidores públicos (Dinsdale et al., 2000).

Por um lado, a cultura, os princípios e os valores específicos do setor público, e por outro, as expectativas de cada usuário, informadas tanto por suas experiências passadas quanto pela informação e pela mídia, são aspectos que devem ser levados em conta nestas avaliações. As percepções são parte da cultura política e cívica englobando valores, crenças, representações e atitudes em relação aos direitos e deveres de cidadania, sendo construídas a partir das experiências presentes e passadas. $\mathrm{Na}$ segunda metade da década de 1990, enquanto nos países mais desenvolvidos o nível de confiança interpessoal ficou em torno de $60 \%$, na América Latina manteve-se em torno de $20 \%$, sendo que no Brasil os resultados foram os piores - 6,3\% (World Values Survey, 2000; Latinobarómetro, 2000).

Em contextos muito desiguais, para certos segmentos da população, a dificuldade usual de conseguir atendimento resulta em baixa expectativa. 0 simples fato de ser atendido já pode produzir satisfação, pois as pessoas não esperam muito das instituições públicas. Diferentes expectativas, seja entre indivíduos de distintos países ou mesmo dentro de um mesmo país que comporte distintas realidades socioculturais, introduzem, portanto, um viés subjetivo, ainda que as metodologias mais comuns de pesquisa de satisfação apresentem seus resultados de forma agregada e quantificada, por freqüências, escalas e índices. A busca de mai or objetividade foi uma das razões para o desenvolvimento do conceito de responsividade.

\section{0 conceito de responsividade nas pesquisas em saúde}

Este conceito, já utilizado na ciência política, diz respeito a quanto as ações governamentais atendem às expectativas e demandas da população. A OM S introduziu-o no campo da avaliação em saúde, como uma alternativa ao conceito de satisfação, para se referir aos elementos não-diretamente ligados ao estado de saúde. Seu fundamento está no pressuposto de que, além de promover e manter a saúde dos indivíduos, o sistema de saúde deve tratá- los com dignidade, facilitar sua participação nas decisões sobre os procedimentos de saúde, incentivar a comunicação clara entre profissio- nal de saúde e usuário e garantir a confidencialidade do histórico médico (De Silva, 2000). Alguns autores definem responsividade como uma combinação de satisfação do paciente com o modo como o sistema age (Blendon et al., 2001).

Responsividade diz respeito ao modo como o desenho do sistema de saúde reconhece e consegue responder às expectativas universalmente legitimadas dos indivíduos em relação aos aspectos não-médicos do cuidado. $0 \mathrm{im}$ portante na introdução desse conceito como uma ferramenta na avaliação de sistemas de saúde é que ele pretende definir princípios de validade universal. Conforme De Silva (1999), o conceito poderia ser visto a partir de dois ângulos: primeiro, do usuário do sistema de saúde como um consumidor, sendo que a maior responsividade atrairia mais consumidores. Segundo, diria respeito à salvaguarda dos direitos dos pacientes a um cuidado adequado.

Esses dois ângulos traduzem-se nas dimensões que orientam as pesquisas sobre responsividade (OM S, 2000b): respeito pelas pessoas e orientação para o cliente. A primeira dimensão - respeito pelas pessoas - refere-se à ética envolvida na interação dos usuários com o sistema de saúde e é, por sua vez, conformada pelas seguintes categorias: dignidade, confidencialidade, autonomia e comunicação. A segundaorientação para o cliente - inclui as categorias que influem na satisfação do paciente, mas não são diretamente ligadas com o cuidado à saúde: atendimento rápido, apoio social, instalações e escolha (Gakidou, 2000).

Os ângulos do consumidor e dos direitos que se traduzem, respectivamente, nas dimensões de orientação para o cliente e respeito pelas pessoas - tiram seu substrato normativo do individualismo, que, como conjunto de valores caracterizando as sociedades modernas, é conformado pelos princípios de autonomia, autodesenvolvimento, privacidade, dignidade humana (Dumont, 1977; Lukes, 1983). Enquanto autonomia, autodesenvolvimento e privacidade correspondem à idéia de liberdade, dignidade humana foi o pressuposto para que a idéia de igualdade tenha se erigido como princípio orientador do desenho das instituições modernas, inclusive a própria separação entre esferas pública e privada.

As dimensões da responsividade pressupõem não apenas uma base de valores, mas correspondem também ao processo de mudanças socioeconômicas e políticas das últimas dé- 
cadas, que significou maior ênfase na escolha individual e responsabilidade. Politicamente, implicou limitar as promessas e expectativas sobre 0 que os governos deveriam fazer. $M$ as ao mesmo tempo, as expectativas das pessoas em relação aos sistemas de saúde são maiores do que nunca. Quase todo dia, uma nova droga ou tratamento, ou um novo avanço da medicina e na tecnologia em saúde é anunciada. Este ritmo do progresso só é pareado pela taxa com que a população procura sua parcela nos benefícios (OMS, 2000b).

Os conflitos clássicos derivados das relações entre liberdade e igualdade no campo da proteção social em saúde alcançam uma dimensão global, não menos pelo peso das agências internacionais, que, a partir da segunda metade do século 20, tem sido decisivo para a difusão dessas orientações normativas. A dimensão liberal do individualismo é afi rmada ao se advogar capacidade de escolha, autonomia e responsabilidade individual, que se estendem ao financiamento e à provisão dos serviços. A contrapartida no plano político é a constatação dos limites dos governos e da atribuição ao mercado de muitas de suas funções anteriores. M as por outro lado, a própria afirmação e difusão do individualismo fazem com que grupos previamente excluídos se autonomizem e se constituam como sujeitos políticos, passando, sob a ótica da igualdade, a reivindicar sua parcela nos benefícios sociais. Os movimentos de luta por autonomia, dignidade e reconhecimento de direitos elevam as expectativas sociais e simbólicas - incluindo aquelas relativas à saúde. São essas mesmas circunstâncias históricas que fazem emergir a noção de empowerment, implicando que categorias sociais destituídas de poder consigam se organizar e vocalizar demandas.

\section{Pressupostos metodológicos das pesquisas de responsividade}

Pesquisas sobre responsividade consideram dois elementos. 0 primeiro é medir o que acontece quando as pessoas interagem com o sistema de saúde, o que implica coletar dados sobre o comportamento, evento ou ação do sistema de saúde. $O$ segundo é medir como as pessoas atendidas pelo sistema de saúde percebem e avaliam "o que acontece".

Trata-se, portanto, de dois procedimentos distintos quanto ao desempenho do sistema de saúde. U ma coisa é medir o que acontece e outra é medir a percepção das pessoas sobre o que acontece, uma vez que as pessoas podem ter uma percepção negativa - ou positiva - sobre o sistema de saúde, mesmo que indicadores sobre "o que acontece" apontem o contrário.

É exatamente em relação ao tipo de perguntas e ao modo de formulá-las que a responsividade difere das pesquisas so bre sati ffação. Se estas últimas costumam perguntar o quanto a pessoa está satisfeita ou não com algum aspecto do serviço de saúde, geralmente levandose em conta suas expectativas prévias, as pesquisas que visam medir responsividade perguntam qual a freqüência com que determinado evento ocorreu.

Com isso pretende-se maior objetividade nas respostas, que não se baseariam apenas na opinião das pessoas, mas também no queacontece quando elas interagem com o sistema. Em vez de se perguntar o quanto a pessoa está satisfeita com o tempo que levou para ser atendida, faz-se perguntas mais objetivas, do tipo "quanto tempo levou para o(a) senhor(a) ser atendido na última vez que veio à unidade de saúde?". As percepções individuais sobre o sistema de saúde seriam contrapostas às "expectativas legitimadas universalmente", ou seja, que independem das expectativas individuais e se baseariam em parâmetros definidos como legítimos e universais para se avaliar os serviços de saúde (Darby, 2000).

Esta metodologia implica formas de se fazer perguntas que reduziriam o fator subjetivo das respostas e o gratitude bias apontado por Bernhart (1999) nas pesquisas de satisfação. Ao se solicitarem informações fatuais e não meramente opiniões, esse viés desapareceria. Resumindo, as pesquisas de responsividade se distinguem das de satisfação do usuário em três pontos:

1. Responsividade avalia o sistema de saúde como um todo, enquanto satisfação do paciente focaliza geral mente as interações clínicas em um setting específico do cuidado de saúde.

2. Responsividade focaliza apenas os aspectos não-médicos, ou seja, não diretamente relacionados ao estado de saúde, ao passo que satisfação do paciente cobre geral mente os aspectos médicos e não-médicos do cuidado.

3. Responsividade avalia as percepções individuais sobre as "expectativas legitimadas universalmente"; já satisfação do paciente representa uma mistura complexa de necessidades percebidas, expectativas determinadas individualmente e experiência de cuidado (DeSilva, 1999).

Como as medidas sobre sati sfação avaliam o quanto os serviços de saúde atendem às ex- 
pectativas, pode ocorrer que as pessoas mais maltratadas - geralmente pertencentes aos grupos mais vulneráveis - diminuam suas expectativas e se satisfaçam com baixos níveis de performance, o que não quer dizer que o sistema de saúde tenha atendido às expectativas legitimadas universalmente. As medidas sobre satisfação podem apagar, assim, diferenças na responsividade experimentada por aqueles para os quais o sistema é menos responsivo e aqueles para os quais o sistema é mais responsivo, levando-se em conta que o primeiro grupo aprendeu a diminuir as expectativas ao avaliar o nível dos serviços (D arby et al., 2000).

Outra vantagem apresentada pelo tipo de perguntas feitas pelas pesquisas de responsividade estaria em sua melhor capacidade para avaliar mudanças. Como os sistemas de saúde mudam ao longo do tempo, para melhor ou para pior, variando também o nível de expectativas dos usuários, as perguntas sobre sati sfação são menos capazes de captar tais mudanças.

O lugar do usuário nos serviços e sistemas de saúde, sobretudo no que se refere à sua condição de sujeito, será ressaltado com as noções de humanização, cujo foco é a dimensão humana, individual e ética do atendimento e a de direitos do paciente, cujo foco é a dimensão da cidadania.

\section{0 conceito de humanização e os direitos do paciente}

No campo da saúde, o conceito de humanização surge como um princípio vinculado ao paradigma de direitos humanos - expressos individual e socialmente - e referidos a pacientes, usuários, consumidores, clientes e cidadãos como sujeitos. A fonte mais recente dos princípios da humanização pode ser buscada na Declaração Universal dos Direitos do Homem (ONU, 1948), que se funda nas noção de dignidade e igualdade de todos os seres humanos: Em outras palavras, o que é devido ao paciente como um ser humano, pel os médicos e pelo Estado, se conformou em grande parte devido a esta compreensão dos direitos básicos da pessoa $<w w w . w h o . i n t / e n t i t y / g e n o m i c / e l s i / e n>$.

0 núcleo do conceito de humanização é a idéia de dignidade e respeito à vida humana, enfatizando-se a dimensão ética na relação entre pacientes e profissionais de saúde. Esta noção começou a ser mais amplamente utilizada na área da saúde a partir dos anos 90, e tam- bém expressa, ao menos em algumas de suas tendências, as críticas à medicalização da atenção médica, surgidas nas décadas anteriores. Nos anos 90, a visão de que a prática médica havia se tornado impessoal e desumana veio orientar propostas para assegurar a proteção dos direitos humanos fundamentais e promover a humanização da assistência a todos os pacientes, incluindo os mais vulneráveis, como as crianças, os pacientes psiquiátricos, os idosos ou os gravemente enfermos (WHO, 1994).

Tanto do ponto de vista normativo quanto empírico, os direitos dos pacientes variam de acordo com contextos culturais e sociopolíticos. São resultado do modo como se estruturam, implementam e distribuem os direitos individuais, sociais e políticos em cada contexto nacional, e também do modo como se instituíram as formas de relação médico-paciente. Tanto o reconhecimento legal de direitos quanto seu enforcement são condicionados por estas variáveis. M esmo assim, vem se construindo crescente consenso internacional em relação aos princípios de que todo paciente deve ter direito fundamental à privacidade, confidencialidade de sua informação médica, em consentir ou recusar tratamento, e ser informado sobre os riscos relevantes dos procedimentos médicos. Estes princípios, difundidos também pelo papel político-institucional dos organismos internacionais na construção do vocabulário e das políticas, são hoje parte das instituições de governança global.

A partir da década de 1990, vários países membros da OM S assinaram declarações, em conjunto, ou próprias, relativas a direitos de pacientes. Um dos objetivos da Declaração sobre a Promoção dos Direitos dos Pacientes na Europa (WHO, 1994) é a implementação do conceito de respeito pelas pessoas e eqüidade em saúde. N este documento, enfatiza-se o livre exercício da escolha individual, bem como a necessidade de se construírem mecanismos que garantam a qualidade do atendimento. A ponta-se que a crescente complexidade dos sistemas de saúde, os progressos da medicina e da ciência e o fato de a prática médica ter se tornado mais arriscada e, em muitos casos, mais impessoal e desumanizada, geralmente envolvendo grande burocracia, mostrou a importância de se reconhecer o direito do indivíduo à autodeterminação e de assegurar garantias de outros direitos de pacientes.

Direitos sociais e direitos individuais dos pacientes são coisas distintas. Enquanto os pri- 
meiros são coletivos e dependem de escolhas e decisões políticas em cada sociedade, os direitos individuais podem ser mais facilmente expressos em termos absolutos e operacionalizados em função de pacientes tomados individualmente. Cobrem áreas como integridade das pessoas, privacidade e conviçcões religiosas e são uma aplicação do paradigma dos direitos humanos no campo da saúde (WHO, 1994).

No Brasil, as reivindicações e a legislação de direitos do paciente, além de expressarem também transformações comuns a outros contextos, são parte do processo de construção da democracia e da cidadania, tanto no plano do desenho institucional do Estado, quanto da sociedade, através de suas organizações e associações. Surgem como direitos individuais vinculados aos direitos sociais em saúde a partir da Constituição de 1988, que estabelece que os serviços de saúde, nos setores público e privado, devem preservar a autonomia das pessoas e garantir que tenham acesso à informação sobre sua saúde (Brasil, 1988).

Com base na Constituição de 1988 e no Código de Ética M édica do Conselho Federal de M edicina, do mesmo ano, diferentes leis e portarias estaduais e federais definiram uma série de direitos de pacientes. Várias cartilhas foram sendo subseqüentemente elaboradas por órgãos oficiais, serviços de saúde e/ou associações de pacientes, como, por exemplo, a CartiIha dos Direitos do Paciente, elaborada a partir do Fórum de Patologias do Estado de São Paulo em 1995, cujos 35 itens convergem com aqueles expressos na Declaração U niversal dos Direitos H umanos e também estão presentes nos códigos de ética médica de outros países. Ressalta-se o direito à privacidade, à informação e ao atendimento respeitoso por parte de todos os profissionais de saúde. Constituiu a base para a lei 10.241, de 17 de março de 1999, sobre os direitos dos usuários dos serviços e ações de saúde no Estado de São Paulo.

A reivindicação de humanização do atendimento por parte dos movimentos sociais e associações de defesa de direitos de pacientes, sobretudo aquelas de certos grupos mais vulneráveis e/ou organizados, como pacientes idosos, portadores de HIV e de distúrbios mentais, é parte desse processo mais amplo de democratização do estado e da sociedade no Brasil.

$O$ feminismo desempenhou um papel crucial para a consolidação de uma das vertentes da humanização do atendimento, ao questionar os valores instrumentais e masculinos da so ciedade industrial, criticar a medical ização do parto e a transformação do nascimento em evento médico (Ehrenreich \& English, 1973; Rich, 1981). Criou, assim, as condições teóricas e políticas para a crítica às condições de assistência à saúde das mulheres e a conquista de direitos específicos na área da reprodução. $\mathrm{Na}$ proposta feminista, humanizar passou a significar recuperar os valores afetivos e as relações de intimidade características da esfera privada, de onde, diriam algumas correntes, o parto nunca deveria ter saído, migrando para o hospital. Logo, estas questões também seriam discutidas nas organizações internacionais (WHO, 1985).

Fortaleza foi sede de duas conferências internacionais promovidas pela OM S para discutir propostas de uma nova cultura de atenção ao parto. Na primeira, J oint Interregional Conference on Appropriate Technology for Birth (WH O, 1985), ocorrida em 1985, o termo humanização não foi utilizado, mas se procurou incorporar as propostas de treinamento de parteiras tradicionais nas áreas rurais. Em 2000, ocorreu a International Conference on the $\mathrm{Hu}$ manization of Childbirth, com a participação da OM S e do U nicef. N esta ocasião, definiu-se humanização como um princípio podendo ser aplicado não apenas ao parto, mas a qualquer aspecto do cuidado, dos doentes terminais, dos idosos, saúde e doença, educação, meio-ambiente, economia, política e cultura. Seria um meio para encorajar e dar poder aos indivíduos e grupos, devendo ser um conceito-chave para o desenvolvimento de uma sociedade sustentável no século 21. Conclamaram-se todos os governos, organizações da ONU, organizações internacionais e organizações não-governamentais a desenvolver ações para promover a humanização (U menai et al., 2001)

A humanização do parto pode ser vista, nas palavras de Diniz, como de certa forma uma versão brasileira, ou latino-americana, daquilo que em países de língua inglesa échamado movimento por um "gentle birth", "respectfull birth", entre outros termos mais imediatamente referidos ao cuidado na relação pessoal (Diniz, 2001).

A noção de humanização do parto passou a ser objeto de várias interpretações e disputas políticas e profissionais, o que, embora pressupondo várias gradações, poderia ser resumido entre duas visões. Por um lado, uma tendência feminista, ecológica, integradora, holística, na qual a mulher não seria separada de seu ambiente na hora do parto - a não ser em casos de complicações - eteria de volta um lugar de cen- 
tro do processo. A atenção materna seria baseada na comunidade, com parteiras, enfermeiras e médicos trabalhando juntos como iguais (Wagner, 1985). Por outro lado, uma perspectiva que não veria contradição entre ética, atendimento digno e acolhedor e o uso de tecnologia e partos hospitalares, ou seja, a ciência médica tal como vem sendo desenvolvida pelo modelo biomédico.

Cada uma destas visões implica modos distintos de atenção ao parto, formação de recursos humanos e pressupostos conceituais para pesquisas. Além disso, não são sempre e tampouco necessariamente antagônicas, podendo dar lugar a modelos contendo um mix entre elementos dos dois pólos.

No final da década de 1990, o conceito de humanização foi estabelecido como princípio de dois programas de saúde no setor público brasileiro, o Programa de H umanização no Pré natal e Nascimento - PHPN (MS, 2002) e o Programa de H umanização da Assistência H ospitalar - PNHAH (MS, 2001), culminando com a Política Nacional de Humanização - PNH (MS, 2003).

O PNHAH Hospitalar surge como uma tentativa de enfrentar os problemas relativos à má qualidade nas várias áreas do atendimento hospitalar, voltando-se para as necessidades de usuários e profissionais. Incentiva 0 acolhimento das pessoas, a promoção de uma cultura de respeito e valorização humana no cuidado aos usuários e a ampliação da qualidade técnica da assistência (MS, 2001).

0 projeto de humanização dos serviços contém, dentre suas ações, a avaliação periódica da satisfação dos usuários e dos profissionais, envolvendo três aspectos fundamentais: a) capacitação permanente dos profissionais de saúde e criação de condições para sua participação na identificação das melhorias necessárias às suas condições de trabal ho; b) criação de condições para a participação ativa do usuário na avaliação da qualidade dos serviços; c) participação da comunidade organizada como parceira dos agentes públicos em ações de apoio e acompanhamento dos serviços.

Por outro lado, o PH PN não pode ser visto sem que se considere sua relação com o PAISM - Programa de Assistência Integral à Saúde da M ulher -, implantado em 1984. Já como um resultado da ação do movimento feminista, o programa inovou ao considerar a saúde da muIher sob a perspectiva da integralidade e, mais tarde, dos direitos reprodutivos.
O PHPN não entrou em detalhes do modelo de parto humanizado - o que é objeto de disputa política e ideológica - mas estabeleceu al guns princípios e preconiza uma série de procedimentos aceitos dentro de uma plataforma mais geral, como um número mínimo de consultas e exames no pré-natal e puerpério, 0 direito da gestante saber previamente e ter assegurado 0 acesso à maternidade onde se dará 0 parto, e a assistência humanizada e segura à mulher e ao recém-nascido no decorrer da gestação, parto e puerpério.

\section{Implicações metodológicas para as pesquisas de humanização}

A utilização do conceito de humanização no campo da saúde é recente, não existindo, ainda, grande quantidade de pesquisas sobre 0 tema. Humanização pode ser objeto de distintas interpretações, as quais orientarão as questões a serem pesquisadas. U ma vez que o conceito de humanização está ligado ao paradigma dos direitos e a cada dia surgem novas reivindicações de direitos, que se remetem às singularidades dos sujeitos, este paradigma vem se tornando complexo e expandindo, alcançando novas esferas sociais e discursivas.

$\mathrm{Na}$ atenção ao nascimento, a corrente feminista vem empreendendo estudos qualitativos, procurando verificar aspectos mais diretamente ligados às categorias de respeito e singularidade dos usuários (Diniz, 2001; Tornquist, 2003).

$\mathrm{Na}$ avaliação de programas específicos de humanização - como o PHPN ou PHAH - os indicadores são definidos segundo os procedimentos preconizados pelos programas. $\mathrm{No}$ atendimento ao parto, por exemplo, podem constituir indicadores: promoção do aleitamento materno; ou então a eliminação/redução de procedimentos não recomendados com base em evidências, como a episotomia, a tricotomia, 0 recurso desnecessário a cesáreas; no que se refere aos aspectos não-médicos do cuidado - foco das pesquisas de responsividade - , alguns indicadores são: presença de acompanhamento na sala de parto e no puerpério; livre acesso de visitantes (que garantem acolhimento e suporte social); contato precoce mãe-bebê; avaliação das usuárias (Boaretto, 2003; Tornquist, 2003). Se para a tendência feminista, o parto de cócoras ou vertical ou as Casas de Parto constituem um indicador de humanização, isso não é visto da mesma forma pelos que defendem o parto 
como um evento sujeito a risco, próprio do ato médico, cujo lugar apropriado seria o hospital.

Diferente de responsividade e satisfação do usuário, humanização e direitos do paciente não constituem conceitos operacionais utilizados em pesquisas de avaliação. Pelo contrário, se os direitos estão sendo respeitados ou se as práticas assistenciais estão seguindo os princípios da humanização, são questões que podem ser avaliadas justamente por pesquisas de satisfação e responsividade. Por exemplo, nos programas de humanização do atendimento no SUS, preconiza-se a avaliação por parte do paciente ou usuário por meio de pesquisas de satisfação, presença de ouvidoria e sua participação em instâncias de gestão. Ou seja, humanização, tal como vem sendo aplicado no campo da saúde, é um conceito que se refere a uma concepção de política garantindo os direitos do(a) usuário(a), os quais são medidos por meio de conceitos operacionais como satisfação e responsividade.

\section{Conclusões}

Se as pesquisas de satisfação deram destaque ao lugar dos pacientes nos serviços e sistemas de saúde, o conceito de responsividade fortaleceu esta posição, dando-Ihe o status de um indivíduo/cidadão, ou seja, de um sujeito de direitos válidos universalmente. 0 sujeito adquiriu um lugar - social, político e simbólico - proeminente, na avaliação dos sistemas e serviços de saúde, seja el e no papel de paciente, usuário, consumidor ou cliente. Esse lugar varia de acordo com o contexto em que cada um desses papéis do sujeito é exercido, mas qualquer um deles, que muitas vezes depende do modo como o sistema de saúde é desenhado, não elimi- na o fato de que todos podem ser abrigados pelo guarda-chuva mais geral dos direitos - individuais e sociais.

A extensão de valores universais para o campo da saúde, inclusive para a avaliação de suas dimensões organizacionais - serviços e sistemas - significou a ampliação do consenso internacional em relação a direitos individuais como direitos humanos, ainda que esse consenso não se aplique quando se trata da formulação de direitos sociais em saúde, o que depende dos valores e das condições históricas próprias dos diferentes contextos nacionais.

Os conceitos e instrumentais metodológicos são construídos como parte de processos históricos e o vocabulário utilizado no campo da saúde está ligado às mudanças no modo de se pensar o papel e o lugar do usuário nos serviços e sistemas de saúde. Se o conceito de satisfação privilegiou o usuário na avaliação da qualidade em saúde, o de responsividade busca tornar mais objetiva a mensuração dos aspectos do cuidado que correspondem às expectativas legítimas de indivíduos e coletividades - ou seja, aqueles mesmo aspectos afirmados pelos princípios gerais que o conceito de humanização supõe. Por outro lado, do ponto de vista das instituições, a responsividade está ligada ao enforcement dos direitos dos pacientes nas sociedades democráticas.

Esperamos que esta discussão possa contribuir para ampliar a compreensão dos significados desses conceitos, bem como suas possibilidades de aplicação em pesquisas de avaliação e nas práticas de saúde. Também com esse propósito, sintetizamos, nos quadros 1 e 2, as categorias que os conformam e suas respectivas definições, ressaltando-se suas similaridades e convergências. 


\section{Colaboradores}

J Vaitsman e GRB Andrade participaram igualmente de todas as etapas da elaboração do artigo.

\section{Agradecimentos}

Agradecemos ao parecerista anônimo as sugestões que muito contribuíram para melhorar a qualidade do artigo, e a sugestão do título.

\section{Referências bibliográficas}

Bernhart M H, Wiadnyana IGP, Wihardjo H \& Pohan I 1999. Patient satisfaction in developing countries. Social Science \& M edicine 48:989-996.

Blendon RJ, Kim M \& Benson JM 2001. The public versus the World $\mathrm{H}$ ealth Organization on health system performance. Health Affairs 20(3):10-20.

Boaretto M C 2003. Avaliação da política de humanização do parto enascimento no M unicípio do Rio de Janeiro. Dissertação de mestrado em Saúde Pública. ENSP/ Fiocruz, Rio de Janeiro.

Brasil 1988. Constituição Federal Brasileira. Leis do SUS. Disponível em <www.rebidia.org.br/noticias/saude/ rede8111.html>. Acessado em outubro de 2003.

Cartwright A 1964. Human relations and hospital care. Reports of the Institute of Community Studies 9:251254.

CNI/Ibope (Confederação Nacional da Indústria/Instituto Brasileiro de Pesquisa), 1999. Pesquisa de opinião.

Conselho Federal de M edicina, 1988. Código de Ética Mé dica. Disponível em <www.cfm.org.br/codetic.htm>. Acessado em julho de 2003.

Coser LA 1956. The functions of social conflict. Free Press. Glencoe, Illinois.

Coser LA 1962. Some functions of deviant behavior and normative flexibility. American Journal of Sociology 68(2):172-181.

Darby C, Valentine N, M urray CJL \& Amala S 2000. Strategy on measuring responsiveness. GPE Discussion $\mathrm{Pa}$ per Series: No. 23. EIP/GPE, WHO.
De Silva A 1999. A framework for measuring responsiveness. GPE Discussion Paper Series № 32. EIP/GPE, WHO.

Diniz CSG 2001. Entrea técnica e os direitos humanos; possibilidades e limites da humanização de assistência ao parto. Tese de doutorado. Faculdade de M edicina, Universidade de São Paulo, São Paulo.

Dinsdale GB, M anson DB, Schmidt F \& Strickland T 2000. M etodologia para medir a satisfação do usuário no Canadá: desfazendo mitos e redesenhando roteiros. Brasília, ENAP, № 20.

Direito do Paciente, 1999. Lei no 10.241 do Estado de São Paulo. Disponível em <www.mp.sp.gov.br/caocivel/ SaudePublica/legisla/Estadual/Lei\%2010241-99\%20 \%20direitos\%20do\%20paciente.doc>. Acessado em novembro de 2003.

Donabedian A 1984. La calidad de la atención médica definición y métodos de evaluación. La Prensa M exicana, M éxico, D.F.

Donabedian A 1990. The Seven Pillars of Quality. Archives of Pathology and Laboratory M edicine 114:1115-1118.

Dumont L 1977. Hommo Aeaqualis. Gallimard, Paris.

Ehrenreich B \& English D 1973. Complaints and disorders - the sexual politics of sickness. The Feminist Press, Nova York.

Gakidou E, M urray CJL \& Frenk J 2000. M easuring preferences on health system performance assessment. GPE Discussion Paper Series: №20. EIP/GPE, WHO.

Kloetzel K, Bertoni AM , Irazoqui M C, Campos VPG \& 
Santos RN 1998. Controle de qualidade em atenção primária à saúde. I - A satisfação do usuário. Cadernos de Saúde Pública, Rio de Janeiro 14(3):623-628.

Kotaka F, Pacheco M L \& Higaki Y 1997. A valiação pelos usuários dos hospitais participantes do programa de qualidade hospitalar do Estado de São Paulo, Brasil. Revista de Saúde Pública 31(2):171-177.

Latinobarómetro 2000. O pinião Pública Latinoamericana. Disponível em <www.latinobarometro.org>. Acessado em outubro de 2003.

Linder-Pelz S 1982. Toward a Theory of Patient Satisfaction. Social Science and M edicine 16:577-582.

Lukes S 1983. Individualism. Basil Blackwell, Londres.

MS (M inistério da Saúde) 2001. Programa de H umanização da Assistência H ospitalar. Secretaria de Assistência à Saúde. Programas e Relatórios no 20. Brasília.

MS (M inistério da Saúde) 2002. Programa de H umanização no Pré-natal e N ascimento. Cartilha de Informações para Gestores e Técnicos. Secretaria de Políticas de Saúde. Disponível em <www.saude.gov.br/sps/areastecnicas/mulher/Cartilha.htm>. Acessado em 13 de dezembro de 2003.

M S (M inistério da Saúde) 2003. HumanizaSU S: política nacional de humanização. M inistério da Saúde, Secretaria-Executiva. N úcleo Técnico da Política $\mathrm{Na}$ cional de Humanização. Brasília.

Oliveira M C \& Rocha M IB 2001. Saúde reprodutiva na esfera pública e política na América Latina. Editora da Unicamp/NEPO, Campinas.

ONU 1948. Declaração U niversal dos Direitos do H omem. Disponível em <www.who.int/entity/genomic/elsi/en>.

Organização M undial de Saúde 2000a. Key Informant Survey. Disponível em <www3.who.int/whosis/menu. $\mathrm{cfm}$ ?path=whosis,surveys\&language $=$ english $>$.

Organização M undial de Saúde 2000b. TheW orld Health Report - H ealth Systems: Improving Performance. Disponível em <www.who.int/whr/en/>.

Parasuraman A, Zeithaml VA \& Berry L 1990. M easuring customer service satisfaction. Disponível em $<w w w$. imt.za/qrater/gaps.html>.

Parasuraman A, Zeithaml VA \& Berry L 1988. SERVIQUAL: a Multiple-Item Scale for measuring customer perceptions of service quality. Journal of Retailing Spring pp.12-40.
Parsons T 1951. The social system. Free Press, N ova York.

Pascoe GC 1983. Patient satisfaction in primary health care: a literature review and analysis. Evaluation and Program Planning 6(3) 185-210.

Ramírez-Sánches TJ, N ájera-Aguilar P \& Nigenda-Lópes G 1998. Percepción de la calidad de la atención de los servicios de salud en M éxico: perspectiva de los usuarios. Salud Pública de M éxico 40:3-12.

Rich A 1981. Of woman born. Bantam Books, N ova York. Rubin HR 1990. Patient Evaluations of H ospital Care - A Review of the Literature. M edical Care 28(9):S3-S9.

Shaw CD 1986. Introducing quality assurance. Kings Fund. Project paper, n. 64, Londres.

Sitzia \& \& Wood N 1997. Patient satisfaction: A review of issues and concepts. Social Science and M edicine 45 (12):1829-1843.

Szasz TS \& Hollender MH 1956. A contribution to the philosophy of medicine. A.M.A. Archives of Internal M edicine 97:585-592.

Tornquist CS 2003. Paradoxos da humanização em uma unidade maternidade no Brasil. Cadernos de Saúde Pública, Rio de Janeiro, 19(Supl. 2):S419-S427.

Vuori H 1987. Patient satisfaction - an attribute or indicator of the quality of care? Q uality Review Bulletin 13:106-108.

U menai et al. 2001. Conference Agreement on the definition of humanization and humanized care. International Journal of Gynecology \& Obstetrics 75(2001): S3-S4.

Wagner M 1985. Having a baby in Europe. European Regional Office. World Health Organization.

Williams B 1994. Patient satisfaction: a valid concept? Social Science and M edicine 38(4):509-516.

World Health Organization 1985. Joint Interregional Conference on A ppropriate Technology for Birth, Fortaleza, 22-26 abril 1985.

World Health Organization 1994. A Declaration of Patients Rights in Europe, European Consultation on the rights of patients. Amsterdam 28-30 M arch 1994.

World Values Survey 2000. Finnish material. Dsiponível em <www.fsd.uta.fi/english/data/meF0154e.html>. Acessado em outubro de 2003.

Artigo apresentado em 10/03/2005

A provado em 19/04/2005

Versão final apresentada em 19/04/2005 